\title{
PREPARATION OF PLYWOOD PANELS USING WASTE MILK POUCHES AS AN ADHESIVE
}

\author{
Siddhartha Arya ${ }^{1}$ \\ https://orcid.org/0000-0003-2662-501X \\ Shakti Chauhan ${ }^{1,2,4}$ \\ https://orcid.org/0000-0003-1108-1291
}

\begin{abstract}
Recycling of single use plastic like milk pouches, oil pouches, etc. for high value products can have significant environmental, social and economic implications. The present study focuses on the utilization of waste milk pouches made out of low-density polyethylene as the bonding agent in preparation of plywood panels. Plywood panels with varying content of polymeric content (milk pouch layers) were prepared and evaluated for physical and mechanical properties. The results indicated that with increase in the dosage of milk-pouch content, both physical as well as mechanical properties of the plywood improved substantially. There was nearly three folds difference in modulus of rupture of panel prepared with $80 \mathrm{~g} / \mathrm{m}^{2}$ and $310 \mathrm{~g} / \mathrm{m}^{2}$ polymer content. Similarly, tensile strength, modulus of elasticity also increased significantly with increase in polymer content. The glue shear strength, which is very important for plywood, was found to be influenced by the quantity of polymer. Glue shear strength for panel with $80 \mathrm{~g} / \mathrm{m}^{2}$ polymer was $0,75 \mathrm{MPa}$ which increased to $1,90 \mathrm{MPa}$ in panel with $310 \mathrm{~g} / \mathrm{m}^{2}$ polymer content. It was observed that for strong bonding it is essential that the quantity of polymer should be sufficient enough to penetrate into the pores of wood creating a mechanical interlocking of veneers. The study opens up the scope of recycling of waste milk pouches in the preparation of formaldehyde free plywood.
\end{abstract}

Keywords: Composites, milk-pouches, plywood, polymer, recycling.

\section{INTRODUCTION}

Plywood is known to have several favourable features such as increased dimension stability, uniformity, large size with improved stress distribution properties and cost effectiveness. It is one of the most used wood based composite materials (Tenorio et al. 2011). Conventionally, plywood is manufactured using thermoset resins such as phenol formaldehyde (PF), urea formaldehyde (UF), melamine formaldehyde (MF), polyurethane (PU), etc. Among these, PF and MF adhesives are the most used in commercial plywood production. Although these adhesives provide good bonding in plywood but the chemicals particularly formaldehyde used in the preparation of these adhesives is known to be toxic. A high dosage of resin i.e. $20 \%$ of total plywood mass may result in concerning formaldehyde emission (Bekhta and Sedliačik 2019). Formaldehyde emission is known to cause eye irritation, sickness syndrome among workers and strongly affects respiratory and nervous system (Jang et al. 2011, Mäkinen et al. 1999). It is one the main cancer-causing agents as reclassified as carcinogenic to human by the International Agency for Research on Cancer. To overcome this issue, many researchers have formulated formaldehyde free adhesive based on soya flour (Jang et al. 2011), starch, palm, etc. (Bono et al. 2010). Thermoplastic resins have also been in trend nowadays as a formaldehyde free adhesive, with different types of thermoplastic resins being used for laminated veneer lumber (LVL) and plywood production (Bekhta et al. 2020). Widely used thermoplastic resins include high density polyethylene (HDPE)

${ }^{1}$ Institute of Wood Science and Technology, Malleswaram, Bengaluru, India.

${ }^{2}$ Indian Plywood Industries Research and Training Institute, Bengaluru, India.

"Corresponding author: shakti32@gmail.com

Received: 26.05.2021 Accepted: 19.11.2021 
(Chang et al. 2018, De Barros Lustosa et al. 2015, Fang et al. 2013, Fang et al. 2014, Fang et al. 2017, Tang et al. 2011) polystyrene (PS) (Borysiuk et al. 2010, Demirkır et al. 2017), low-density polyethylene (LDPE) (Follrich et al. 2006, Cui et al. 2010, Ibragimov et al. 2017), polypropylene (PP) (Kajaks et al. 2012, Song et al. 2016, Song et al. 2017) and polyvinyl chloride (PVC) (Matuana et al. 1998, Song et al. 2017).

Utilization of thermoplastic as a potential adhesive in plywood opens up an opportunity to recycle waste thermoplastic material. With the abundant usage, the disposal of plastic is one of the major concerns for the environment due to its slow degradation. Among different thermoplastics, polyethylene terephthalate (PET) and polyethylene (both HDPE and LDPE) are the major plastic waste generators, contributes to about $75 \%$ of plastic waste in India (CPCB 2015). Used and disposed PET plastic is easy to collect, is relatively priced higher for the rag-picker and nearly $90 \%$ is recycled. However, PE plastic specially materials like post consumption empty milk pouches, oil pouches, etc., which are daily household waste in most of the developing nations, are recycled little (Aryan et al. 2019). This particular type of waste tends to clog sewage, drainage, etc. resulting in urban problems during rainy seasons. Otherwise also, if left alone in landfills and open lands, these waste plastics gets disintegrated into micro-plastics over a long period contributing to major environmental issues by entering the food web (Chamas et al. 2020). Literature suggests that milk pouches only accounts to a total of $74 \%$ of total PE waste while the rest comes from PE shopping bags (Aryan et al. 2019). Recycling and utilization of such waste for other products can have substantial implications in dealing with the problems associated with such wastes (Aranda-García et al. 2020). This waste material can effectively be used as an adhesive for mainly plywood which can also address the issues of formaldehyde emission from such panels along-with the recycling of waste material.

This study focuses on utilization of waste milk pouch as a binding material in preparation of plywood panels. Amid alarming environmental issues, PE may be utilised as binding agent in production of plywood thereby increasing its recyclability and helping in source reduction. In the present paper, one litre LDPE milk pouches waste collected from household were layered in between veneers and hot pressed to prepare formaldehyde free plastic bonded plywood (PBP). Besides removing major plastic waste, it will also contribute in safeguarding environment from formaldehyde emission.

\section{MATERIALS AND METHODS}

Rotary peeled $2 \mathrm{~mm} \pm 0,5 \mathrm{~mm}$ thick veneers of Melia dubia wood were sourced from Indian Plywood Industries Research and Training Institute, Bengaluru. The species is commonly used in manufacturing of plywood panels. The average moisture content of the veneers was $8 \% \pm 2 \%$ at the time of panel preparation. Post-consumer waste milk pouches of 40 and 60 micrometre thickness and density of $0,92 \mathrm{~g} / \mathrm{cm}^{3}$ (LDPE based as specified on the pouches) were collected from the residential areas nearby the laboratory (Figure 1). The pouches were thoroughly cleaned with detergent and water in order to remove dirt, oil and fat content of milk and were finally dried in oven at $50{ }^{\circ} \mathrm{C}$ to remove the moisture.

Three-layer plywood panels of dimension $300 \mathrm{~mm} \times 300 \mathrm{~mm} \times 4,8 \mathrm{~mm}$ were prepared with varying propor-tion of LDPE films amounting to polymer content of $80 \mathrm{~g} / \mathrm{m}^{2}, 105 \mathrm{~g} / \mathrm{m}^{2}, 210 \mathrm{~g} / \mathrm{m}^{2}$ and $310 \mathrm{~g} / \mathrm{m}^{2}$ between the two veneers. The arrangement of veneer was such that the core layer grain direction was perpendicular to face veneer grain i.e. criss-cross arrangement. In between two adjacent layers of wood veneers, milk pouches in the form of film were placed without any chemical additives The panel with $80 \mathrm{~g} /$ $\mathrm{m}^{2}$ polymer content was prepared with half-litre milk pouches of dimensions $150 \mathrm{~mm} \times 120 \mathrm{~mm}$. These pouches were having polymer film thick-ness of 40 micrometer and each pouch weighed about $1,45 \mathrm{~g}$. Whereas, when one-litre capacity milk pouches (dimensions - $220 \mathrm{~mm} \times 150 \mathrm{~mm}$; weight $-3,70 \mathrm{~g}$ ) having plastic layer thickness of 60 micrometer were used in single layer, double layer and triple layer, it amounted to $105 \mathrm{~g} / \mathrm{m}^{2}, 210 \mathrm{~g} / \mathrm{m}^{2}$ and $310 \mathrm{~g} / \mathrm{m}^{2}$ of plastic con-tent between the veneers for $300 \mathrm{~mm} \times 300 \mathrm{~mm}$ sized panels. The assembly of veneers and LDPE sheets was placed in a preheated hydraulic hot press of 500 tons capacity maintained at $150{ }^{\circ} \mathrm{C}-155^{\circ} \mathrm{C}$ (Figure 2). The composites were pressed at a specific pressure of 12 $\mathrm{kg} / \mathrm{cm}^{2}$ for 10 minutes. The panels were removed from the hot press and placed in a cold press at a pressure of $30 \mathrm{~kg} / \mathrm{cm}^{2}$ to avoid warping in the panel due to differential cooling of polymer and wood veneer. Though the melting point of LDPE ranges from $105^{\circ} \mathrm{C}-110^{\circ} \mathrm{C}$ (Alkan et al. 2018), for the better flow of polymer in the pores of wood veneers to achieve good bonding between the ve-neers, the temperature was kept much higher than its melting point. Higher temperature is also required due to low thermal conductivity of wood. Keeping hot press temperature much higher than the polymer melt tempera-ture has been suggested by other researchers for such panels (Bekhta and Sedliačik 2019, Fang et al. 2013). 


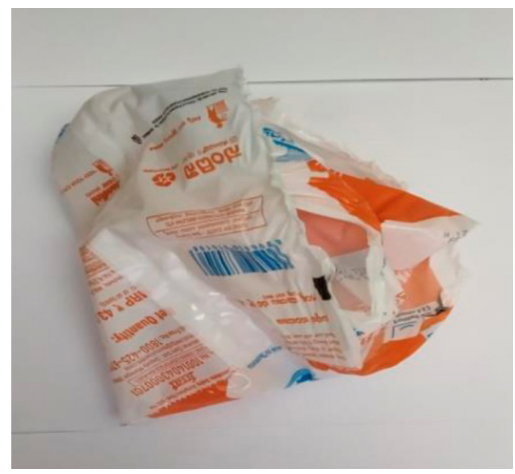

Figure 1: Waste milk pouches.

\begin{tabular}{|c|}
\hline Caul Plate \\
\hline Veneer \\
\hline Milk Pouch \\
\hline Veneer \\
\hline Milk Pouch \\
\hline Veneer \\
\hline Caul Plate \\
\hline
\end{tabular}

Figure 2: Assembly of polymer bonded plywood.

\section{Physical and mechanical properties}

Five panels of plywood were manufactured at each polymer content levels. The prepared panels were conditioned at $23{ }^{\circ} \mathrm{C} \pm 2{ }^{\circ} \mathrm{C}$ and $65 \% \pm 5 \%$ relative humidity for seven days. Thereafter, test specimens were extracted from the panels. The panels were tested for various physical properties namely density, adhesion of plies (Knife test), water absorption (WA), thickness swelling (TS) and volumetric swelling (VS). WA and swelling tests were carried out for 2 hours and 24 hours duration. Density was calculated by measuring the mass and volume (volume by displacement method) as per IS 1734 (1983). Percentage of TS and WA were calculated from the difference between initial and final reading after 2 hour and 24 hours (Parthiban et al. 2019) as per IS 2380 (1977) using Equation 1 and Equation 2.

$$
\begin{aligned}
& T S \%=\left(\frac{T_{f}-T_{i}}{T_{i}}\right) x 100 \\
& W A \%=\left(\frac{W_{f}-W_{i}}{W_{i}}\right) x 100
\end{aligned}
$$

Where $\mathrm{T}_{i}$ and $\mathrm{T}_{f}$ are the initial and final thickness (in $\mathrm{mm}$ ) respectively, and $\mathrm{W}_{i}$ and $\mathrm{W}_{f}$ are the initial and final weight (in grams), respectively for the specific period of time. The adhesion strength between the veneers was tested with knife test or delamination test after 2 hours of boiling in water as per IS 1734 (1983). 
Mechanical properties namely modulus of rupture (MOR) and modulus of elasticity (MOE) were tested as per ASTM D790-15 (2016). Tensile strength was evaluated as per ASTM D638-14 (2016) and glue shear strength (GSS) was evaluated using IS 1734 (1983). Shimadzu make universal testing machine (Model autograph-AG, $10 \mathrm{kN}$ capacity) was used for testing mechanical properties. Since the dimensions of the prepared panels were only $300 \mathrm{~mm} \times 300 \mathrm{~mm}$, it was not possible to extract samples as per Indian standards for testing of plywood panels (IS 1734 (1983)) and therefore the composite samples were tested with procedure prescribed for reinforced thermoplastic composites. Sample dimension for MOE and MOR determination was $100 \mathrm{~mm} \times 12 \mathrm{~mm} \times 4,8 \mathrm{~mm}$. The span length for three-point bending test was as at least 14 times the thickness of the sample and the loading rate was $0,6 \mathrm{~mm} / \mathrm{min}$. For tensile strength, the span length was $100 \mathrm{~mm}$ and the loading rate was $1 \mathrm{~mm} / \mathrm{min}$.

For glue shear strength (GSS) test, samples were tested in dry condition for the bond class 1 (EN 314-2). The samples were prepared by making saw cut up to glue line as shown in Figure 3. The grain direction of the ply between the glue-line under test is perpendicular to the length of the test specimen. The loading rate was $0,6 \mathrm{~mm} / \mathrm{min}$. For each test, five replicates were tested. The adhesion phenomenon was also analysed by optical microscopy Nikon and model no. C-W 10 X B/22.

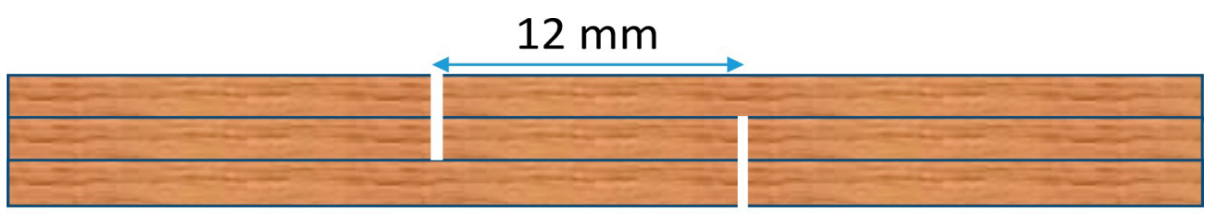

Figure 3: Schematic diagram for saw-cut in plywood panel for glue-shear strength.

The data was analysed using SPSS software for statistically significant differences in properties with respect to polymer content. Duncan test was performed to identify significantly different group for each property.

\section{RESULTS AND DISCUSSION}

Physical properties of the prepared plastic bonded plywood (PBP) at varying proportion of polymer content are given in Table 1 . Density of the plywood panels was ranging from $0,53 \mathrm{~g} / \mathrm{cm}^{3}$ to $0,64 \mathrm{~g} / \mathrm{cm}^{3}$ which is much higher than the density of Melia dubia wood. The air dry density of Melia dubia is reported to be between the range of $0,42 \mathrm{~g} / \mathrm{cm}^{3}$ to $0,52 \mathrm{~g} / \mathrm{cm}^{3}$ (Khali et al. 2017, Saravanan et al. 2013). The higher density of the panel is due to densification of wood attributed to compression during hot-press and also due to presence of polymer. The density of PBP was found to increase with the polymer content in the panel. The density of panels with $80 \mathrm{~g} / \mathrm{m}^{2}$ polymer dosage was found to be $0,53 \mathrm{~g} / \mathrm{cm}^{3} \pm 0,003 \mathrm{~g} / \mathrm{cm}^{3}$ and for $310 \mathrm{~g} / \mathrm{m}^{2}$ polymer dosage it was $0,64 \mathrm{~g} / \mathrm{cm}^{3} \pm 0,02 \mathrm{~g} / \mathrm{cm}^{3}$. The increase in density of composite with increasing polymer dosage is attributed to the relatively higher density of LDPE $\left(0,92 \mathrm{~g} / \mathrm{cm}^{3}\right)$ as compared to wood. 
Table 1: Physical properties of plywood with different LDPE content. Values in parenthesis is standard deviation.

\begin{tabular}{|l|c|c|c|c|}
\hline \multirow{2}{*}{\multicolumn{2}{|c|}{ Properties }} & \multicolumn{4}{c|}{ Polymer content } \\
\cline { 2 - 5 } & $80 \mathrm{~g} / \mathrm{m}^{2}$ & $105 \mathrm{~g} / \mathrm{m}^{2}$ & $210 \mathrm{~g} / \mathrm{m}^{2}$ & $310 \mathrm{~g} / \mathrm{m}^{2}$ \\
\hline Density $\left(\mathrm{g} / \mathrm{cm}^{3}\right)$ & $0,53(0,003)$ & $0,57(0,03)$ & $0,61(0,07)$ & $0,64(0,02)$ \\
\hline Water absorption - 2 h(\%) & $21,54(1,36)$ & $17,40(2,20)$ & $15,72(2,90)$ & $14,68(2,22)$ \\
\hline Water absorption - 24 h(\%) & $55,33(2,27)$ & $52,18(5,80)$ & $43,39(5,70)$ & $40,23(3,13)$ \\
\hline Volumetric swelling - 2 h(\%) & $5,18(1,96)$ & $4,40(0,61)$ & $3,95(0,63)$ & $2,94(2,13)$ \\
\hline Volumetric swelling - 24 h(\%) & $7,61(1,12)$ & $7,01(0,20)$ & $6,26(0,67)$ & $5,84(1,35)$ \\
\hline Thickness swelling - 2 h(\%) & $4,48(1,61)$ & $3,88(0,45)$ & $3,19(0,69)$ & $2,8(2,32)$ \\
\hline Thickness swelling - 24 h(\%) & $6,09(0,84)$ & $6,04(0,30)$ & $5,52(0,86)$ & $5,35(1,44)$ \\
\hline
\end{tabular}

WA (\%) of PBP after 2 hours and 24 hours of soaking in water for $80 \mathrm{~g} / \mathrm{m}^{2}$ was recorded to be 21,54 \% and $55,33 \%$ respectively. Panels with higher polymer content absorbed relatively less water. After 24 hours of WA, PBP with $310 \mathrm{~g} / \mathrm{m}^{2}$ polymer content absorbed $15 \%$ less water as compared to PBP with $80 \mathrm{~g} / \mathrm{m}^{2}$ polymer content. TS on WA of PBP after 2 hours of soaking was inversely proportion to the dose of polymer as the TS for PBP with $310 \mathrm{~g} / \mathrm{m}^{2}$ polymer content was $37,5 \%$ lower than in PB with for $80 \mathrm{~g} / \mathrm{m}^{2}$ polymer content. The same trend was observed for 24 hours test however the swelling in boards with $80 \mathrm{~g} / \mathrm{m}^{2}$ was only $12,5 \%$ higher than observed in boards with $310 \mathrm{~g} / \mathrm{m}^{2}$ polymer content. The reduced WA and TS on increasing polymer loading may be attributed to the slower water absorption rate by the core veneer due to its encapsulation by the polymer film which acts as a barrier. However, long term absorption may lead to similar TS irrespective of polymer loading. This is also evident from the large difference in WA and swelling properties after 2 hours test and the difference tends to reduce after 24 hours test in boards prepared with two extreme polymer loadings. De Barros Lustosa et al. (2015) reported 3,21 \% TS in LVL panel prepared with Trattinnickia burserifolia veneer and HDPE at $150 \mathrm{~g} / \mathrm{m}^{2}$ polymer loading and $2,82 \%$ in panel with $350 \mathrm{~g} / \mathrm{m}^{2}$ polymer loading however after 24 hours of soaking TS for both $150 \mathrm{~g} / \mathrm{m}^{2}$ and $350 \mathrm{~g} / \mathrm{m}^{2}$ polymer loading was similar. Similarly, Bekhta and Sedliačik (2019) prepared plywood from Alnus gultinosa veneer with HDPE and found the WA range from $38,86 \%$ to $44,58 \%$ for 2 hours which is much high compare to PBP prepared in this study. Knife test carried out after two hours of soaking in boiling water revealed complete delamination at $80 \mathrm{~g} / \mathrm{m}^{2}$ polymer content. However, at higher polymer levels bonding was intact without any delamination and wood failure was observed during the test indicating strong bonding between the veneers.

\section{Mechanical properties}

Mechanical properties of the composite material are very important as it determines their suitability for different applications. The prepared panels were tested for MOR, MOE, tensile strength and GSS. The mechanical properties of panels prepared with different polymer content are shown in Figure 4, Figure 5, Figure 6 and Figure 7.

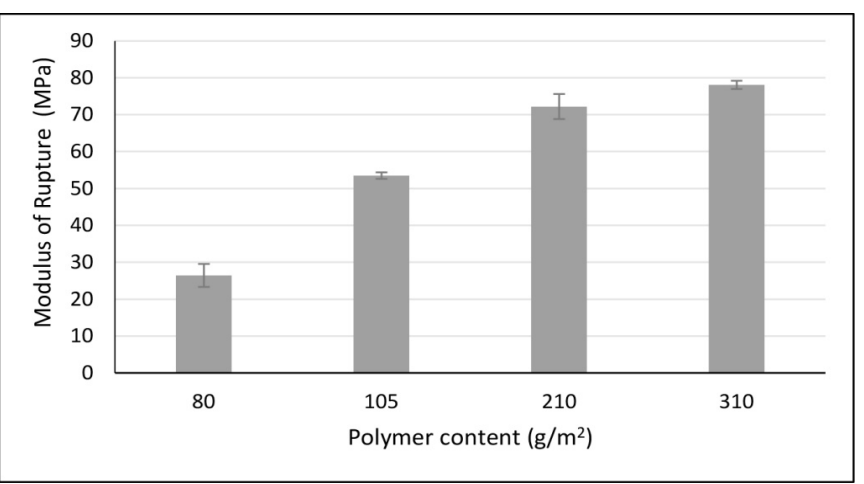

Figure 4: MOR of plywood panels at varying polymer content. 
There was an increasing trend in MOR as the dose of LDPE was increased from $80 \mathrm{~g} / \mathrm{m}^{2}$ to $310 \mathrm{~g} / \mathrm{m}^{2}$ (Figure 4). During the processing, some fractures are formed in veneers and on increasing the doses the molten HDPE is expected to penetrate inside the pores and repair the veneer contributing to the enhanced mechanical properties. MOR of panels with $80 \mathrm{~g} / \mathrm{m}^{2}$ polymer content was observed to be only $26,41 \mathrm{MPa}$, as the dose of polymer was not enough to form the bond between veneers. With the increase in polymer content, the strength value gradually increased and MOR value at $310 \mathrm{~g} / \mathrm{m}^{2}$ polymer content was $78,10 \mathrm{MPa}$ which was nearly three folds higher than at $80 \mathrm{~g} / \mathrm{m}^{2}$ polymer content. The strength of the panels prepared in this study with higher polymer content $\left(>80 \mathrm{~g} / \mathrm{m}^{2}\right)$ were higher than the conventional plywood prepared using veneers of the same species and UF as the adhesive, which was reported to be in the range of $48,66 \mathrm{MPa}$ to $63,9 \mathrm{MPa}$ (Khali et al. 2017). MOR of the plywood depends on the strength of the individual layer and adhesion strength. At low polymer content, adhesion strength between the veneers is expected to be poor resulting in the failure of the core veneer as the MOR of Melia dubia wood across the grain was $14,86 \mathrm{MPa}$ as against $81,95 \mathrm{MPa}$ along the grain. With the improved adhesion at higher polymer content, the MOR of plywood was close to that of solid-wood MOR which suggests that the core veneer had little influence on flexural strength of the plywood. Fang et al. (2017) observed MOR for poplar plywood bonded with HDPE film of 0,06 mm thickness to be 73,34 MPa. In an another study, Fang et al. (2013) prepared poplar plywood bonded with varying doses of HDPE ranging from 61,6 to $246 \mathrm{~g} / \mathrm{m}^{2}$ and found that MOR of the panel increased with increasing film dosage up to $185 \mathrm{~g} / \mathrm{m}^{2}$ and thereafter stabilized which is in congruence with the results obtained in this study where after polymer loading of $210 \mathrm{~g} / \mathrm{m}^{2}$ there was very little change in MOR. MOR values at 210 and $310 \mathrm{~g} / \mathrm{m}^{2}$ polymer content were not significantly different.

MOE of the composites did not exhibit any significant variation with polymer content (Figure 5). For 80 $\mathrm{g} / \mathrm{m}^{2}$ doses of LDPE milk pouches, MOE was observed to be $8642 \mathrm{MPa} \pm 526 \mathrm{MPa}$ and on increasing the doses to $105 \mathrm{~g} / \mathrm{m}^{2}, 210 \mathrm{~g} / \mathrm{m}^{2}$ and $310 \mathrm{~g} / \mathrm{m}^{2}$ the value of MOE was $8874,9 \mathrm{MPa} \pm 870 \mathrm{MPa}, 8523,6 \mathrm{MPa} \pm$ $247 \mathrm{MPa}$ and $9022,95 \mathrm{MPa} \pm 891 \mathrm{MPa}$, respectively. The uniform MOE of composites irrespective of polymer content indicates that interfacial adhesion is not influencing MOE. This is mainly attributed to the fact that MOE of a laminate mainly depends on the corresponding properties of each of the plies and their relative thickness as it follows the law of mixture (Chauhan et al. 2005).

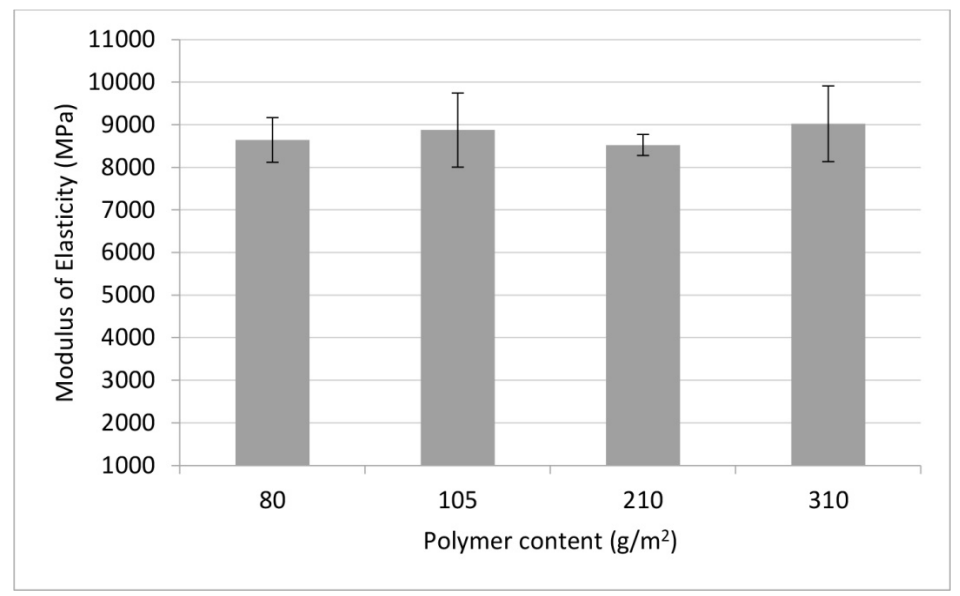

Figure 5: MOE of plywood panels at varying polymer content.

Tensile strength is generally considered to be an indicator of interfacial strength. In case of poor interfacial adhesion between the veneers, the core veneer is expected to fail very quickly as the tensile strength of wood across the grain is extremely poor. This was evident from the result as the tensile strength of the panel was $21,28 \mathrm{MPa}$ at $80 \mathrm{~g} / \mathrm{m}^{2}$ polymer content (Figure 6). The polymer quantity was not enough to cover the complete surface of the veneers and to penetrate into the pores and vessels during hot pressing resulting in poor strength. As the polymer content was increased, the bonding between the veneers also improved and tensile strength was $48,90 \mathrm{MPa}$ at $310 \mathrm{~g} / \mathrm{m}^{2}$ loading. However, it appears that $210 \mathrm{~g} / \mathrm{m}^{2}$ was optimal polymer content layer between the veneers as there was no significant difference (at $\alpha=0,05$; Duncan test) in tensile strength at $210 \mathrm{~g} / \mathrm{m}^{2}$ and $310 \mathrm{~g} / \mathrm{m}^{2}$ polymer loading. 


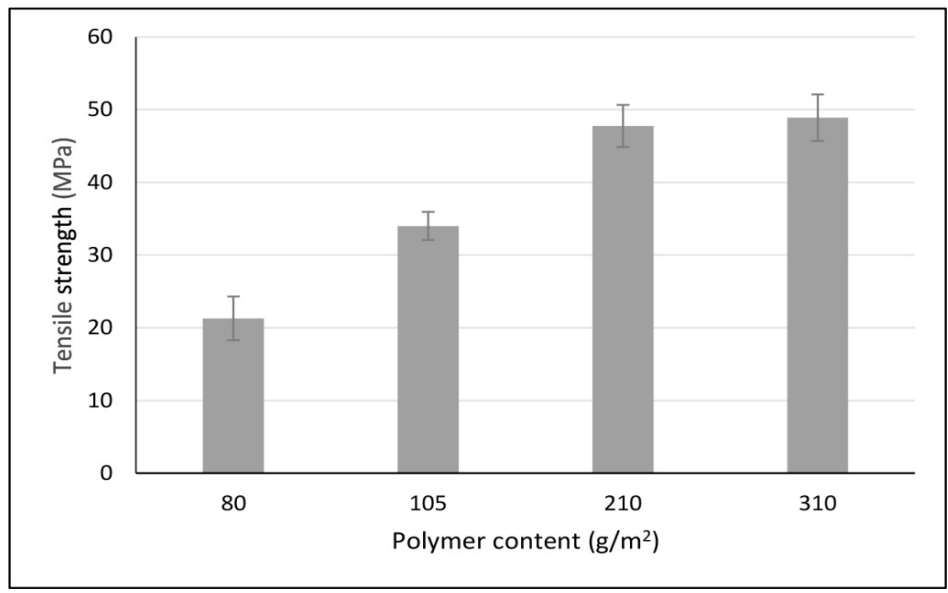

Figure 6: Tensile strength of plywood panels at varying polymer content.

Yue et al. (2019) studied the tensile strength of laminated wood plastic composites prepared from maleic anhydride treated poplar veneer and $0,3 \mathrm{~mm}$ thick thermoplastic sheet with a ratio of PP and PE at 1:1 and found it to vary from 20,49 MPa to 31,47 MPa with varying wood to plastic ratio (w/w basis) which is lower than the results obtained in this study. In this study untreated veneers were used and also no coupling agent was incorporated in the assembly.

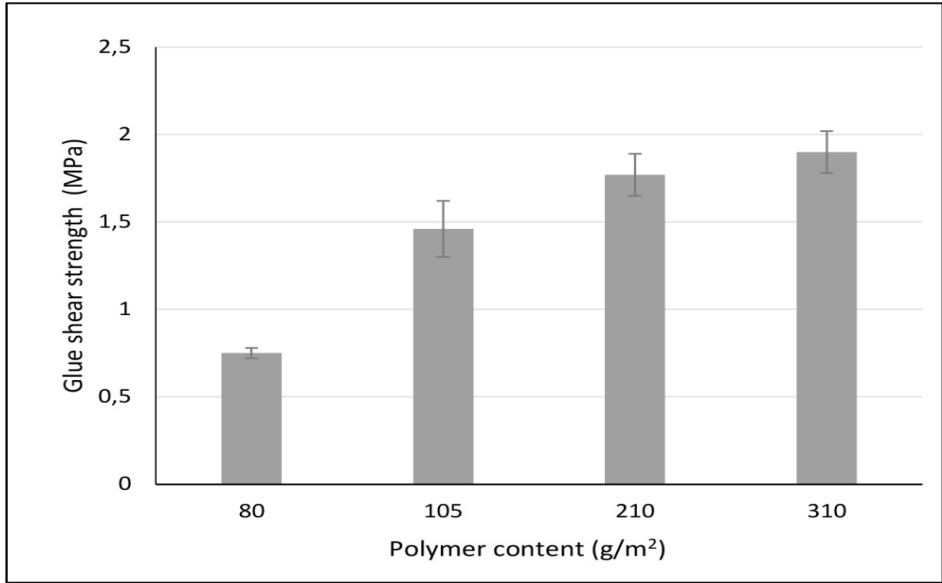

Figure 7: Glue shear strength of plywood panels at varying polymer content.

Further to analyse the adhesion strength, GSS was determined which suggests the adhesion strength between the veneers. GSS was found to be $0,75 \mathrm{MPa} \pm 0,028 \mathrm{MPa}$ in panel with $80 \mathrm{~g} / \mathrm{m}^{2}$ dose of polymer and increased by nearly $150 \%$ at $310 \mathrm{~g} / \mathrm{m}^{2}$ polymer loading (Figure 7). This was attributed to filling up of larger proportion of voids and lumen space of the two adjacent veneers by polymer during hot pressing as the polymer content is increased forming improved mechanical bond. There was a sharp increase $(\sim 100 \%)$ in GSS when polymer content increased from $80 \mathrm{~g} / \mathrm{m}^{2}$ to $105 \mathrm{~g} / \mathrm{m}^{2}$ but thereafter the strength increased gradually. The Duncan test revealed that the GSS was statistically differing significantly at each polymer dosage level. Chang et al. (2018) assessed the GSS of poplar plywood and found that on increasing the dosage there was increase in maximum penetration depth and effective penetration depth. The variation in other mechanical properties, particularly strength properties, with polymer content is associated with the adhesion strength between the veneers and with improved adhesion at higher polymer content the strength properties also exhibited the improvement on the expected lines.

\section{Optical microscopy}

The penetration of polymer was further investigated using optical microscopy for different doses in PBP. It was found that LDPE was able to penetrate and flow into the vessel and porous structure of wood. 
Mechanical bond was formed which lead to mechanical interlocking and providing the strength to plywood. It was observed that when the LDPE was $80 \mathrm{~g} / \mathrm{m}^{2}$ (Figure $8 \mathrm{a}$ ), polymer is sparsely spread over veneers and there were discontinuous phases of polymer over veneer surface. At lower polymer content, polymer did not penetrate into the vessels and pores resulting in poor interlocking and thus poor mechanical strength. This is further influenced by the poor chemical compatibility of wood with LDPE leading to poor interfacial adhesion between the two veneers. Whereas in panels with higher polymer loading (Figure 8b, Figure 8c, Figure 8d), there is a thick and uniform dispersion of polymer at the glue-line and also the molten polymer has penetrated inside the vessels of the veneer leading to improved mechanical bonding between the two veneers.
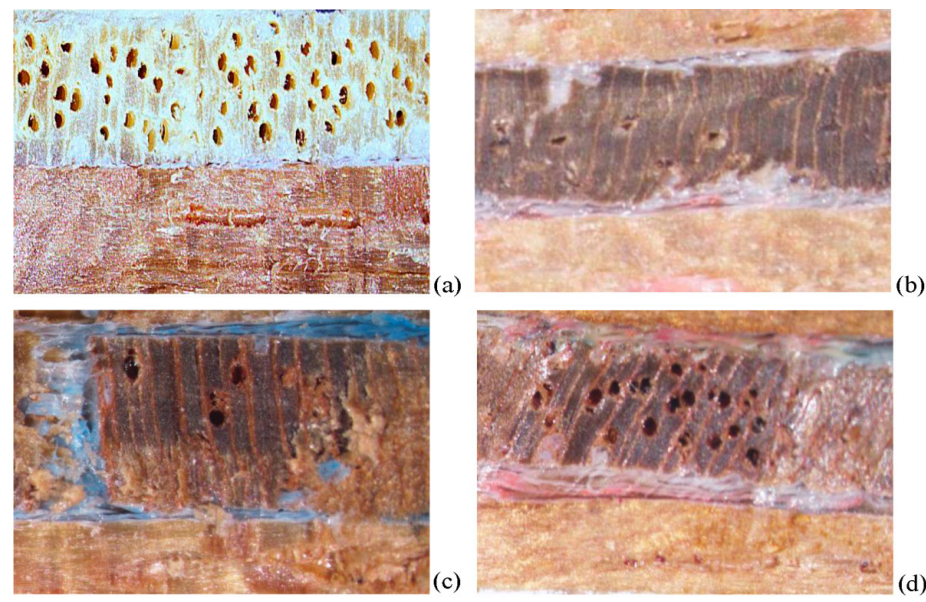

Figure 8: Optical microscopy image of plywood prepared at varying polymer content. (a) $80 \mathrm{~g} / \mathrm{m}^{2}$, (b) $105 \mathrm{~g} / \mathrm{m}^{2}$, (c) $210 \mathrm{~g} / \mathrm{m}^{2}$ and (d) $310 \mathrm{~g} / \mathrm{m}^{2}$.

\section{CONCLUSIONS}

The study demonstrated the suitability of recycling waste milk pouches (LDPE based) as the bonding agent in preparing plywood panels. The formaldehyde free PBP will serve two purposes i.e.us age of waste plastic including milk pouches as well as reduction in formaldehyde emission from the wood panels which is a major concern. For proper melting and embedding of polymer in plywood, it is essential to keep the hot press temperature higher than the polymer and also the quantity of polymer has to be at the optimal level. Low level of polymer content resulted in delamination of veneers on knife test indicating poor bonding. In this study, plywood prepared with $210 \mathrm{~g} / \mathrm{m}^{2}$ polymer content was found to be the optimum level as there was no significant difference in physical and mechanical properties and the panel possessed good bonding strength without glue-line failure. The improvement in properties is mainly attributed to the mechanical bonding of the veneers due to penetration of hot-molten polymer into wood ultra-structure of the adjacent veneers.

\section{REFERENCES}

Alkan, Ü.; Kılıç, M.; Karabul, Y.; Çağlar, M.; İçelli, O.; Güven-Özdemir, Z. 2018. X-ray irradiated LDPE/PP blends with high mechanical and dielectric performance. J Appl Polym Sci 135(31): 1-10. https://doi.org/10.1002/app.46571

Aranda-García, F.J.; González-Pérez, M.M.; Robledo-Ortíz, J.R.; Rosa, C.S.; Espinoza, K.; Ramírez-Arreola, D.E. 2020. Influence of processing time on physical and mechanical properties of composite boards made of recycled multilayer containers and HDPE. J Mater Cycles Waste Manag 22: 2020-2028. https://doi.org/10.1007/s10163-020-01092-5

Aryan, Y.; Yadav, P.; Samadder, S.R. 2019. Life Cycle Assessment of the existing and proposed plastic waste management options in India:A case study. J Clean Prod 211: 1268-1283. https://doi.org/10.1016/j. jclepro.2018.11.236

ASTM. 2016. Standard test method for flexural properties of unreinforced and reinforced plastics and electrical insulating material. ASTM. D790-15. 2016. ASTM International: West Conshohocken, PA. 
ASTM. 2016. Standard test method for Tensile properties of plastic. ASTM. D638-14. 2016. ASTM International: West Conshohocken, PA.

Bekhta, P.; Sedliačik, J. 2019. Environmentally-friendly high-density polyethylene-bonded plywood panels. Polymers 11(7): 1166. https://doi.org/10.3390/polym11071166

Bekhta, P.; Müller, M.; Hunko, I. 2020. Properties of thermoplastic bonded plywood: Effects of the wood species and types of the thermoplastic films. Polymers 12 (11):2582. https://doi.org/10.3390/polym12112582

Bono, A.; Farm, Y.Y.; Krishnaiah, D.; Ismail, N.M.; Yee, L.Y.K.; Lee, L.M. 2010. Palm kernel based wood adhesive. J Appl Sci 10(21): 2638-2642. https://doi.org/10.3923/jas.2010.2638.2642

Borysiuk, P.; Mamiński, M.Ł.; Parzuchowski, P.; Zado, A. 2010. Application of polystyrene as binder for veneers bonding-the effect of pressing parameters. European Journal of Wood and Wood Products 68: 487489. https://doi.org/10.1007/s00107-010-0418-x

Chamas, A.; Moon, H.; Zheng, J.; Qiu,Y.; Tabassum,T.; Jang, J.H.; Abu-Omar, M.; Scott, S.L.; Suh, S. 2020. Degradation rates of plastics in the environment. ACS Sustain Chem Eng 8(9): 3494-3511. https://doi.org/10.1021/acssuschemeng.9b06635

Chang, L.; Tang, Q.; Gao, L.; Fang, L.; Wang, Z.; Guo, W. 2018. Fabrication and characterization of HDPE resins as adhesives in plywood. European Journal of Wood and Wood Products 76 (1): 325-335. https://doi.org/10.1007/s00107-016-1117-z

Chauhan, S.S.; Kenneth M, E.; Walker, J. 2005. Differences in acoustic velocity by resonance and transit-time methods in an anisotropic laminated wood medium. Holzforschung: 428-434. https://doi.org/10.1515/ HF.2005.070

CPCB. 2015. Assessment andquantification of plastics waste generation in major cities. A report pubished by Central Pollution Control Board, Ministry of Environment Forests and Climate Change, Government of India.https://optoce.no/wp-content/uploads/2019/03/CPCBCIPET-Assessment-and-Quantification-of-Plastics-Waste_2015.pdf

Cui, T.; Song, K. L.; Zhang, S. B. 2010. Research on utilizing recycled plastic to make environment-friendly plywood. Forestry Studies in China 12(4): 218-222. https://doi.org/10.1007/s11632-010-0401-y

De Barros Lustosa, E.C.; Del Menezzi, C.H.S.; De Melo, R.R. 2015. Production and properties of a new wood laminated veneer/high-density polyethylene composite board. Mater Res 18(5): 994-999. https://doi.org/10.1590/1516-1439.010615

Demirkır, C.; Öztürk, H.; Çolakoğlu, G. 2017. Effects of press parameters on some technological properties of polystren composite plywood. Kastamonu Univ J Fores Fac 17(3): 517-522. https://doi.org/10.17475/ kastorman.285645

Fang, L.; Chang, L.; Guo, W.J.; Chen, Y.; Wang, Z. 2014. Influence of silane surface modification of veneer on interfacial adhesion of wood-plastic plywood. Appl Surf Sci 288: 682-689. https://doi.org/10.1016/j. apsusc. 2013.10 .098

Fang, L.; Chang, L.; Guo, W.J.; Ren, Y.P.; Wang, Z. 2013. Preparation and characterization of wood-plastic plywood bonded with high density polyethylene film. European Journal of Wood and Wood Products 71(6): 739-746. https://doi.org/10.1007/s00107-013-0733-0

Fang, L.; Xiong, X.; Wang, X.; Chen, H.; Mo, X. 2017. Effects of surface modification methods on mechanical and interfacial properties of high-density polyethylene-bonded wood veneer composites. J Wood Sci 63(1): 65-73. https://doi.org/10.1007/s10086-016-1589-9

Follrich, J.; Müller, U.; Gindl,W. 2006. Effects of thermal modification on the adhesion between spruce wood (Picea abies Karst.) and a thermoplastic polymer. European Journal of Wood and Wood Products 64(5): 373-376. https://doi.org/10.1007/s00107-006-0107-y 
Ibragimov, A.; Vasilkin, A.; Fedotov, A. 2017. Research physic-mechanical properties of composite materials on the base of peeled veneer and low density polyethylene. IOP Conf. Ser: Earth Environ Sci 90: 012062. https://doi.org/10.1088/1755-1315/90/1/012062

IS. 1983. Bureau of Indian Standards, Methods of test for plywood. IS.1734. 1983. New Delhi. https://www.iitk.ac.in/ce/test/IS-codes/is.1734.1-20.1983.pdf

IS. 1977. Bureau of Indian Standards, Methods of test for wood particle boards and boards from other lignocellulosic material. IS. 2380. 1977. New Delhi. https://www.iitk.ac.in/ce/test/IS-codes/is.2380.1-21.1977. pdf

Jang, Y.; Huang, J.; Li, K. 2011. A new formaldehyde-free wood adhesive from renewable materials. Int J Adhes Adhes 31(7): 754-759. https://doi.org/10.1016/j.ijadhadh.2011.07.003

Kajaks, J.; Reihmane, S.; Grinbergs, U.; Kalnins, K. 2012. Use of innovative environmentaly friendly adhesives for wood veneer bonding. Pro Est Acad Sci 61(3): 207-211. https://doi.org/10.3176/proc.2012.3.10

Khali, D.P.; Kumar, A.; Shrivastava, P.2017. Plywood for general purpose (interior grade) of selected different progenies of Melia composita Benth. J Ind Acad Wood Sci14(2): 139-145. https://doi.org/10.1007/ s13196-017-0199-5

Mäkinen, M.; Kalliokoski, P.; Kangas, J. 1999. Assessment of total exposure to phenol-formaldehyde resin glue in plywood manufacturing. Int Arch Occup Environ Health 72(5): 309-314. https://doi.org/10.1007/ s004200050380

Matuana, L.M.; Balatinecz, J.J.; Park, C.B. 1998. Effect of surface properties on the adhesion between PVC and wood veneer laminates. Polym Eng Sci 38(5): 765-773. https://doi.org/10.1002/pen.10242

Parthiban, K.T.; Dey, S.; Krishnakumar, N.; Das, A. 2019. Wood and plywood quality characterization of new and alternate species amenable for composite wood production. Wood Fiber Sci 51(4): 1-8. https://wfs.swst.org/index.php/wfs/article/view/2857

Saravanan, V.; Parthiban, K.T.; Kumar, P.; Marimuthu, P. 2013. Wood characterization studies on $\mathrm{Me-}$ lia dubia cav. for pulp and paper industry at different age gradation. Res Jof Recent Sci 2(ISC-2012): 183-188. https://citeseerx.ist.psu.edu/viewdoc/download?doi=10.1.1.1086.2620\&rep=rep1\&type=pdf

Song, W.; Wei, W.; Li, X.; Zhang, S. 2016. Utilization of polypropylene film as an adhesive to prepare formaldehyde-free, weather-resistant plywood-like composites: Process optimization, performance evaluation, and interface modification. BioResources 12(1): 228-254. https://ojs.cnr.ncsu.edu/index.php/BioRes/ article/view/10359

Song, W.; Wei, W.; Wang, D.; Zhang, S. 2017. Preparation and properties of new plywood composites made from surface modified veneers and polyvinyl chloride films. BioResources 12(4): 8320-8339. https://ojs.cnr.ncsu.edu/index.php/BioRes/article/view/BioRes_12_4_8320_Song_New_Plywood_Composites

Tang, L.; Zhang, Z.G.; Qi, J.; Zhao, J.R.; Feng, Y. 2011. The preparation and application of a new formaldehyde-free adhesive for plywood. Int $J$ Adhes Adhes 31(6): 507-512. https://doi.org/10.1016/j.ijadhadh.2011.04.005

Tenorio, C.; Moya, R.; Muñoz, F. 2011. Comparative study on physical and mechanical properties of laminated veneer lumber and plywood panels made of wood from fast-growing Gmelina arborea trees. $J$ Wood Sci 57(2): 134-139. https://doi.org/10.1007/s10086-010-1149-7

Yue, K.; Wang, L.; Xia, J.; Zhang, Y.; Chen, Z.; Liu, W. 2019. Experimental research on mechanical properties of laminated poplar wood veneer/Plastic sheet composites. Wood Fiber Sci 51(3): 320-331. https://doi.org/10.22382/wfs-2019-030 